\title{
COMPARATIVE ANALYSIS OF GLOBAL DIGITAL ELEVATION MODELS AND ULTRA-PROMINENT MOUNTAIN PEAKS
}

\author{
Carlos H. Grohmann \\ Institute of Energy and Environment, University of São Paulo, 05508-010, - São Paulo, SP, Brazil - guano@usp.br
}

\author{
Commission IV, WG IV/3
}

KEY WORDS: GDEM, SRTM, ETOPO1, GTOPO30, ACE2, GMTED, Topographic Prominence

\begin{abstract}
:
Global Digital Elevation Models (GDEMs) are datasets of vital importance for regional-scale analysis in areas such as geomorphology, [paleo]climatology, oceanography and biodiversity. In this work I present a comparative assessment of the datasets ETOPO1 (1' resolution), GTOPO30, GLOBE, SRTM30_PLUS, GMTED2010 and ACE2 (30") against the altitude of the world's ultra prominent peaks. GDEMs' elevations show an expected tendency of underestimating the peak's altitude, but differences reach 3,500 m. None of the GDEMs captures the full range of elevation on Earth and they do not represent well the altitude of the most prominent peaks. Some of these problems could be addressed with the release of NASADEM, but the smoothing effect caused by moving-window resampling can only be tackled by using new techniques, such as scale-adaptative kernels and curvature-based terrain generalisation.
\end{abstract}

\section{INTRODUCTION}

Global Digital Elevation Models (GDEMs) are datasets of vital importance for regional-scale analysis in areas such as geomorphology, climatology, oceanography and biodiversity. Geomorphological studies at sub-continental (Fielding et al., 1994; Miliaresis, 2006) to continental or global scale (Harrison et al., 1983; Cogley, 1985), as well as the relationships between large-scale landforms (i.e., mountain ranges, basins) and tectonic settings (Mayer, 2000), need to be carried out with digital elevation data.

Among the applications of DEMs with global coverage, one can cite its applications in development of geopotential global models (Arabelos, 2000), evaluation of glacier volume change (Berthier et al., 2006), climatic modelling (Moore et al., 1991; Thomas et al., 2004) or even in navigation systems for commercial aviation (Fox et al., 2008).

Although global elevation datasets are available at fine resolutions such as the 30m global SRTM (NGA, 2014; JPL, 2014), ASTER GDEM (Tachikawa et al., 2011), ALOS World3D (Takaku et al., 2014) or WorldDEM (Krieger et al., 2009), coarser resolution data still is widely used, specially in global-scale climatic simulations where grid cell size constrains the computational cost of numeric models and results are usually presented at resolutions of $2^{\circ}$ or coarser (Thompson and Pollard, 1995; Schmidt et al., 2006). Global climatological data has only recently been made available at 1' resolution (New et al., 2002; Hijmans et al., 2005).

Berry (1999) points the risks of a comparison of GDEMs based only on statistical correlations, since issues which are common to two datasets will not be highlighted and that errors in mosaicking data from different sources are not usually observed in hypsometric or contour line maps given the large variability of elevation in the planet's topography. This author cites the importance of using an independent dataset for analysis and uses satellite radar altimetry data from ERS-1 and ERS-2 (European Remote-Sensing Satellite) for comparisons with GLOBE and JGP95E (Berry, 1999) and with SRTM (Berry et al., 2007).

In this work a comparative assessment of GDEMs is presented for the following datasets: ETOPO1 (1' spatial resolution, approx. 2 $\mathrm{km}$ at the Equator), GTOPO30, GLOBE, SRTM30_PLUS, ACE2 and GMTED2010 (30", $1 \mathrm{~km})$. The GDEMs' elevation was compared with a database of the altitude of mountain peaks with ultra topographic prominence, in order to evaluate the sensibility of regional-scale data to features distinctively marked in the landscape, although of little areal expression.

\section{GLOBAL DEMS}

In this section, a brief descriptions of the GDEMs analysed in this is study is presented. The datasets are described in a chronological order.

\subsection{GTOPO30}

In 1996 the US Geological Survey (USGS) released GTOPO30, a global DEM with 30" ( 1 km) spatial resolution. This model was developed by the USGS Earth Resources Observation and Science (EROS) with cooperation from the NGA, National Aeronautics and Space Administration (NASA), United Nations Environment Programme/Global Resource Information Database (UNEP/GRID), US Agency for International Development (USAID), Instituto Nacional de Estadistica Geografica e Informatica (INEGI - Mxico), Geographical Survey Institute (GSI - Japan), the Manaaki Whenua Landcare Research (New Zealand) and the Scientific Committee on Antarctic Research (SCAR) (Gesch et al., 1999).

GTOPO30 is certainly an important milestone in the development of Geomorphometry, given its availability and level of detail. The model was widely used in regional and continental-scale analysis such as climatic modelling, hydrology, geomorphology and geometrical adjustment of satellite imagery.

\subsection{GLOBE}

The GLOBE project (Global Land One-Kilometer Base Elevation) aimed at producing a global DEM with 30" of spatial resolution, managed by an international team, in an independent manner (the 'independence' refers to restrictions imposed by federal 
agencies of several countries and contracts with military laboratories) (Hastings and Dunbar, 1998; GLOBE Task Team et al., 1999).

Two other global DEMs with 30" resolution were developed in the course of the years of GLOBE production. The Jet Propulsion Laboratory (JPL) developed a DEM from DTED data for internal use at NASA, while the USGS created GTOPO30. These two DEMs were used in GLOBE, although its differential was in data contributed directly by the National Oceanic and Atmospheric Administration (NOAA) and the fact that it was designed as a continuous program, where new data would be added as they became available.

\subsection{ACE/ACE2}

The global DEM ACE (Altimeter Corrected Elevations), with 30" resolution, was created by combining ERS-1 (European Radar Satellite) radar altimetry with public topographic data (Berry et al., 2000). With the release of SRTM, the techniques developed for the first ACE version were used to enhance SRTM data. ACE2 (Berry et al., 2008) is based on 03" SRTM data between $60^{\circ} \mathrm{N}$ and $60^{\circ} \mathrm{S}$ latitude and GLOBE and ACE data for higher latitudes.

A comparison of radar altimetry data with SRTM showed strong differences in the Amazon and Congo forests (with higher elevations for SRTM, due its characteristic of representing canopy height in densely vegetated areas). In those areas, SRTM data was replaced by radar altimetry. In the other areas, altimetry data was used to warp SRTM to decrease the elevation differences (Smith and Berry, 2011).

\subsection{SRTM30_PLUS}

The Shuttle Radar Topography Mission was a cooperation among NASA, NGA, DoD, the Deustches Zentrum für Luft- und Raumfahrt (DLR, Germany) and the Agenzia Spaziale Italiana (ASI, Italy). The STS-99 space mission of the Endeavour Space Shuttle flew during 11 days in February 2000; its main objective was the topographical mapping of continental areas between $60^{\circ} \mathrm{N}$ and $60^{\circ} \mathrm{S}$ (about $80 \%$ of the Earth's land masses) with radar interferometry (InSAR). Data was produced with two sensors: Spaceborne Imaging Radar-C (SIR-C, $5.6 \mathrm{~cm}$ wavelength) and X-band Synthetic Aperture Radar (X-SAR, $3.1 \mathrm{~cm})$. A detailed review of the SRTM mission is given by Farr et al. (2007).

SRTM30_PLUS (Becker et al., 2009) is a global DEM with 30" resolution, created by combining data from several projects. In the continental areas, data is mainly from USGS SRTM30, a resampling of original SRTM data to 30". For high latitudes, where there is no SRTM data available, data is from GTOPO30. Oceanic areas are based on Smith and Sandwell (1997) with 01' resolution between latitudes $81^{\circ} \mathrm{N}$ and $81^{\circ} \mathrm{S}$; arctic bathymetry is from the current version of IBCAO (Jakobsson et al., 2012). Higher resolution data was incorporated from the LDEO Ridge Multibeam Synthesis Project, JAMSTEC Data Site for Research Cruises, and the NGDC Coastal Relief Model.

\subsection{ETOPO1}

ETOPO1 has 01' resolution ( $2 \mathrm{~km})$ and, as its predecessors, is based on multiple data sources (Amante and Eakins, 2009). Continental areas are based mainly on SRTM30_PLUS and the ocean bathymetry is from Sandwell and Smith (1997). For high latitudes of the northern hemisphere GLOBE data was used for land elevation and IBCAO for oceans. Regional bathymetric data were used for the Baltic Sea, Caspian Sea, Great Lakes, Golf of California, Sea of Japan, Mediterranean Sea ans the coastal zone of the USA.

There are two versions of ETOPO1: one with the elevation of ice masses in polar regions ("Ice surface" version) and one with the topography of the bedrock underneath these ice sheets ("Bedrock" version). For Antarctica, data derives from BEDMAP and for Greenland from the National Snow and Ice Data Center (Bamber, 2001)

\subsection{GMTED2010}

The Global Multi-resolution Terrain Elevation Data (GMTED 2010 ) is the product of a collaboration between the USGS and NGA to produce a global DEM to be the successor of GTOPO30, GLOBE and others of similar spatial resolution (Danielson and Gesch, 2011). It is available in three resolutions (approximately $1,000 \mathrm{~m}, 500 \mathrm{~m}$ and $250 \mathrm{~m}$ ) and its main data source is a SRTM version with 01 " resolution, restricted to the NGA and not available to the general public.

Other data sources include the Canadian Digital Elevation Data (CDED), SPOT 5 Reference 3D, NED for the continental USA and Alaska, GEODATA 9 Second Digital Elevation Model for Australia, DEMs for Antarctica and Greenland from laser altimetry (ICESat and GLAS data) and satellite radar (ERS-1 data).

GMTED2010 is distributed as raster grids where each grid cell stores a numeric value that represents a geographic attribute for that unit of space (mean, median, minimum, maximum, standard deviation, subsampling and breakline emphasis). In this work the grid representing the mean values of elevation at $1000 \mathrm{~m}$ resolution was selected, since it is considered a fair approximation of data acquired by a remote sensor at this resolution (Grohmann et al., 2010), and because only the 'mean' and 'subsampling' layers contains elevation data for Greenland and Antarctica.

\section{METHODS}

\subsection{Data Processing}

Data processing was performed in GRASS-GIS 6.4.5 (Neteler et al., 2012; GRASS Development Team, 2014) through Python scripts (Python Software Foundation, 2013) using the Pygrass library (Zambelli et al., 2013) to access GRASS datasets. Statistical analyses were performed with the Python libraries Scipy, Numpy and Matplotlib (Oliphant, 2006; Hunter, 2007; The SciPy community, 2013).

\subsection{Topographic Prominence}

The topographic prominence of a mountain is defined as the vertical distance between its peak and the lowest contour line encircling it (that is, a pass or a sadlle) but not another higher peak (Llobera, 2001; Maizlish, 2003; Podobnikar, 2012) (Fig. 1).

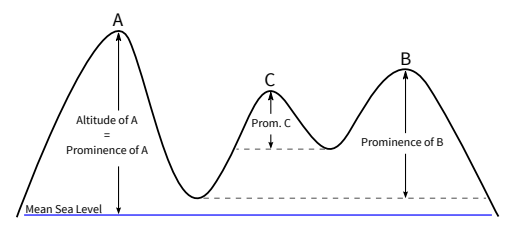

Figure 1: Topographic prominence of a mountain.

It is also known as primary factor, drop, relative height, island height or re-ascent, and can be seen as the elevation of a summit 
Table 1: Descriptive statistics of differences between altitudes of ultra prominent peaks and elevation of analysed GDEMs.

\begin{tabular}{lrrrrrrrr} 
Dataset & Min. & Max. & Mean & Median & Std.Dev. & Skewness & Kurtosis & R-squared \\
\hline SRTM30_PLUS & 3.0 & 3354.0 & 346.48 & 271.55 & 253.46 & 1.94 & 5.79 & 0.946 \\
GMTED2010 & 6.0 & 3310.0 & 335.12 & 267.55 & 233.97 & 1.91 & 6.57 & 0.978 \\
ACE2 & 9.0 & 3433.0 & 427.00 & 323.11 & 344.29 & 1.97 & 5.90 & 0.898 \\
GTOP030 & 0.0 & 3520.0 & 385.12 & 267.58 & 383.09 & 1.99 & 5.99 & 0.889 \\
GLOBE & 0.0 & 3520.0 & 428.33 & 326.52 & 355.18 & 1.90 & 5.63 & 0.965 \\
ETOPO1 & 2.0 & 3359.0 & 554.84 & 495.74 & 277.60 & 1.56 & 4.32 & 0.977 \\
\hline
\end{tabular}

relative to the highest point to which one must descend before reascending to a higher summit (Maizlish, 2011).

Ultra-prominent peaks (or simply ultras) are those with topographic prominence of $1,500 \mathrm{~m}(4,921 \mathrm{ft})$ or more. A database of the world's ultras was downloaded from the http://peaklist . org website (Maizlish, 2011) as a KMZ file with 1,524 entries and attributes such as peak's name, location (country, coordinates), elevation, prominence, alternative names and additional comments. According to the author, the peak's elevation was obtained from different sources for each geographical region (see http://peaklist.org/ultras.html).

\section{RESULTS}

The differences between altitudes of ultra-prominent peaks and analysed GDEMs are shown as scatter plots and histograms in Fig. 2. In the scatter plots, the thin grey line represents a $1: 1$ ratio and the best-fit line is in green. Due the high asymmetry of the histograms, a Kolmogorov-Smirnov test was performed to evaluate their goodness of fit with long-tailed distributions. The exponentially modified Gaussian distribution (EMG) presented the best results. Descriptive statistics of the differences between ultras and GDEMs are shown in Table 1. Values of Mean, Median, Standard Deviation, Skewness and Kurtosis were calculated based on the EMG fitted to the data.

A general tendency of underestimation of elevation in the GDEMs is expected, due the lower resolution of older datasets and by the smoothing effect of resampling finer DEMs into coarser ones (Carter, 1992; Zhang and Montgomery, 1994; Chow and Hodgson, 2009; Grohmann, 2015), as is the case with SRTM30_PLUS and GMTED2010.

All datasets show a positive asymmetry in the distribution of the errors, with means larger than the medians. Differences for ETOPO1 show less asymmetry than the other datasets, with the smaller skewness and larger median.

Values of mean and median are very similar for GMTED2010/ GTOPO30 and for ACE2/GLOBE, which can indicate that data from the older GDEMs was used as source for the younger ones. This is documented in the case of ACE2, but there is no indication of such practice for GMTED2010.

Visually, ACE2 shows more dispersion about the best-fit line than the other datasets, while ETOPO1 shows less dispersion. GTOPO30 and GLOBE are very similar, indicating a similar source for elevation data in mountainous areas.

Fig. 3 maps with the location of ultra-prominent peaks, coloured according to the standard deviation of the differences between altitude of peak and analysed GDEM. Larger values occur, as expected, in remote areas such as the Himalayas, Antarctica and Greenland. Other than these regions, SRTM30_PLUS show high differences in the Patagonian Andes (Fig. 3A), and GMTED2010 is similar to SRTM30_PLUS, but with smaller differences in Greenland (Fig. 3B).

ACE2 shows more peaks with large altitude differences in the Himalayas and the Guyana Shield than others GDEMs (Fig. 3C). apparent in the Himalayas, Antarctica, Greenland, equatorial Andes, Guyana Shield, Patagonia and Southeast Asia.

\section{DISCUSSIONS AND CONCLUSIONS}

None of the GDEMs captures the full range of elevation on Earth and they do not represent well the altitude of the most prominent peaks.

For all datasets, maximum differences exceed $3,300 \mathrm{~m}$, which is not compatible with smoothing from resampling, and may indicate positioning errors of the peaks in the ultras database. In regions with steep, mountainous terrain, and lack of high-quality topographic maps, the coordinates of peaks in the maps used as source may not be accurate, and a small difference in its positioning can be sufficient for sampling a pixel located in the footslopes of a mountain.

All datasets that use SRTM as source show large errors in high latitude regions, that is, areas outside the limits of SRTM coverage, in which ancillary data was used (e.g., GTOPO30). These discrepancies can be addressed with data from newer GDEMs generated with satellite InSAR (WorldDEM) or optically derived GDEMs, such as ASTER GDEM or ALOS World3D.

NASADEM will be the product of an effort within the NASA MEaSUREs program to combine SRTM elevation with data from other sensors, to generate a void-free, global DEM with 01" $(\sim 30 \mathrm{~m})$ resolution. SRTM raw data will be reprocessed with improved algorithms (better handling of Beam Adaptive Tracker, phase unwrapping, etc) and use of NASA cloud computing resources. Ancillary data include ASTER GDEM V2, SPOT stereo and NED. ICESat altimetry will be used to improve ground control on existing elevation data. Processing and distribution will be on a continent-by-continent basis, with releases throughout 2016 (Kobrick et al., 2011; Kobrick and Crippen, 2015).

A lower-resolution (i.e., 30" or coarser) GDEM derived from NASADEM has the potential to address most of the differences between GDEMs and the elevation of ultra-prominent peaks showed in this paper, except for the smoothing effect of resampling a DEM into a coarser one.

To create a global DEM at a low resolution and still be able to depict the fine-scale elements of the landscape such as mountain peaks, the averaging-by-moving-window approach must be either abandoned or at least complemented by new techniques. Scale-adaptative kernel filtering or curvature-based methods have been proposed for classification and generalisation of landforms (Wood, 1996; Jenny et al., 2011; Jasiewicz and Stepinski, 2013) and could provide the basis for a better representation of the global topography. 

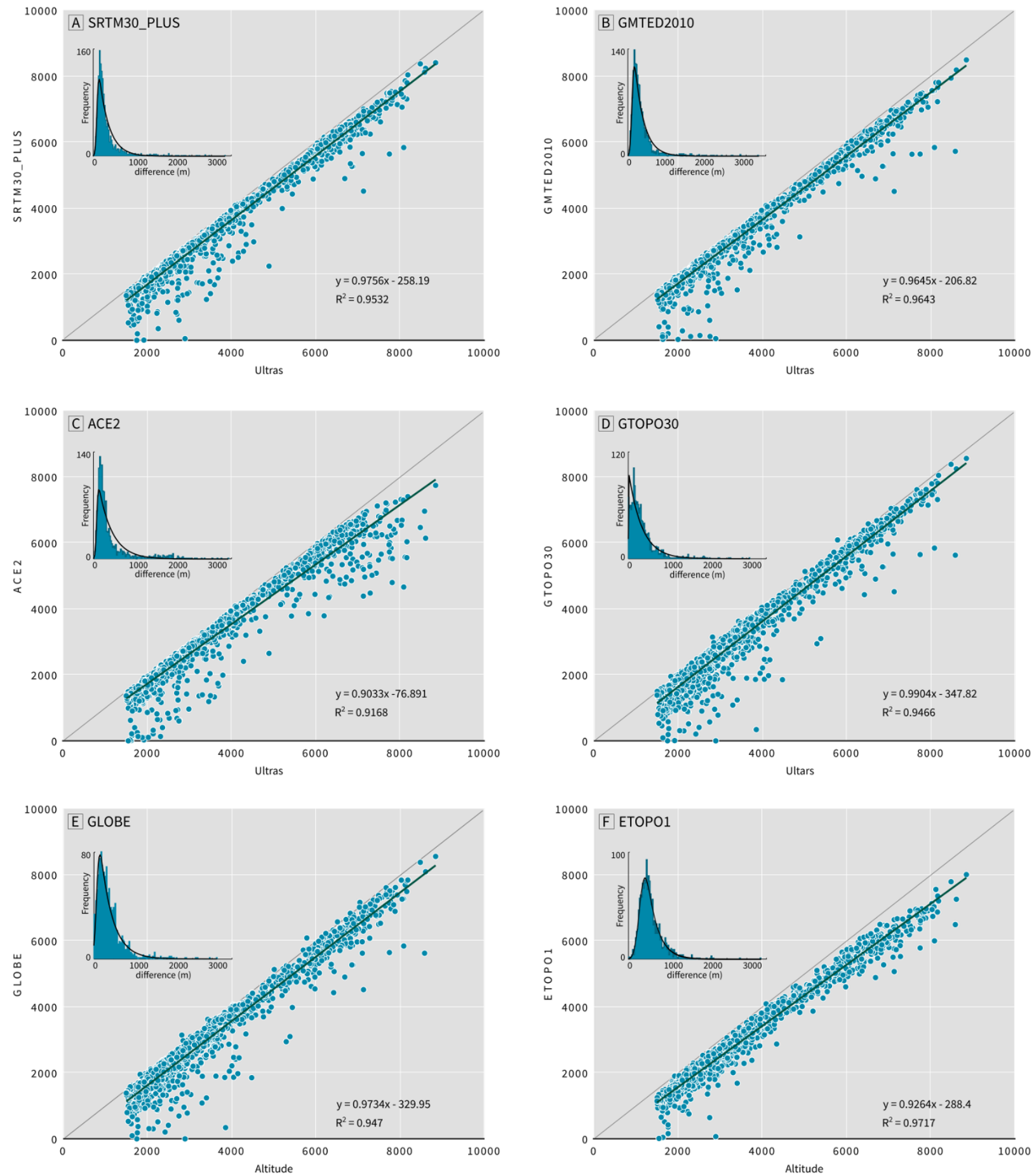

Figure 2: Histograms and scatter plots of differences between altitudes of ultra-prominent peaks and analysed GDEMs. A) SRTM30_PLUS; B) GMTED2010; C) ACE2; D) GTOPO30; E) GLOBE; F) ETOPO1. 


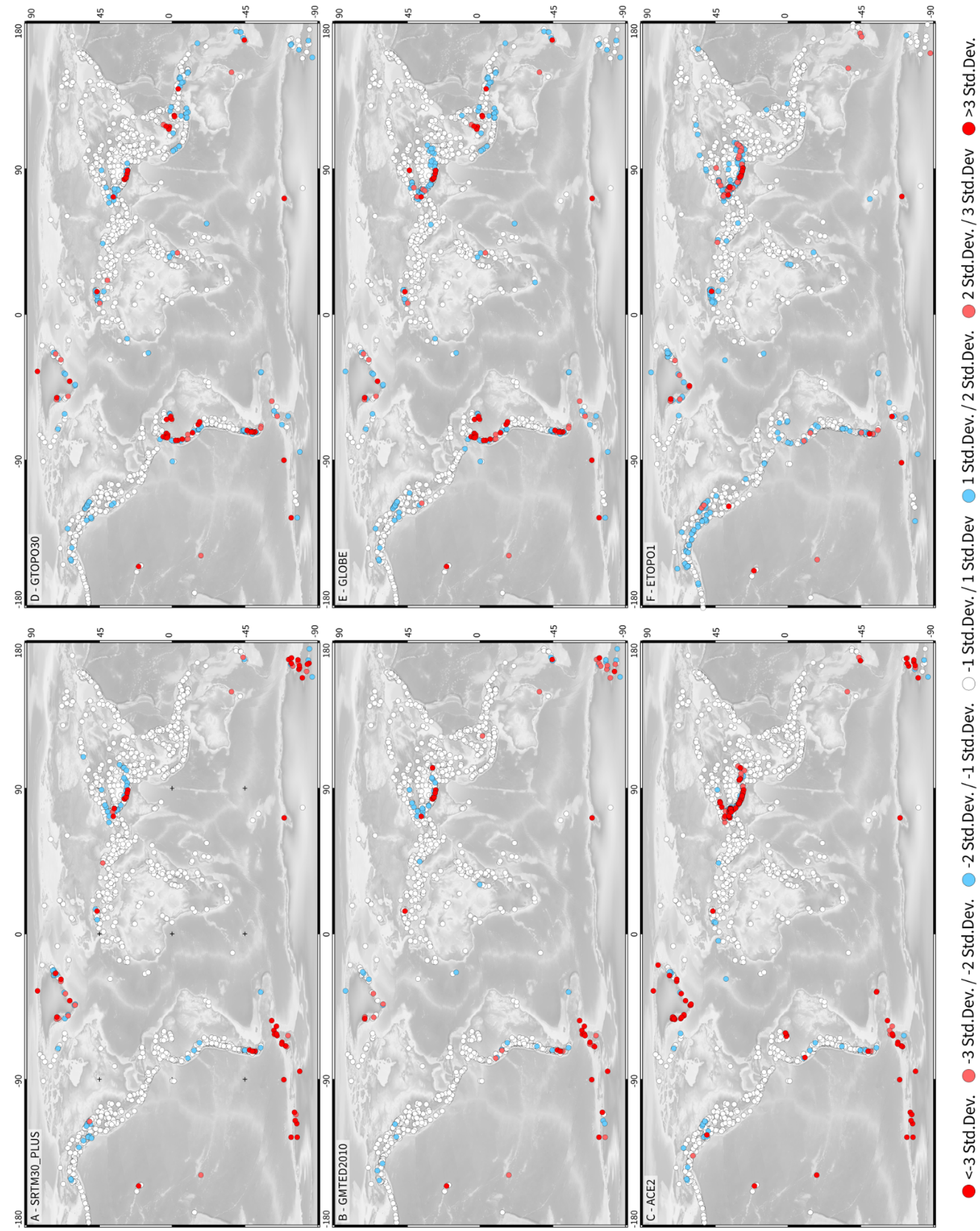

Figure 3: Map of ultra-prominent peaks, coloured according to the standard deviation of the differences between altitude of peak and analysed GDEM. A) SRTM30_PLUS; B) GMTED2010; C) ACE2; D) GTOPO30; E) GLOBE; F) ETOPO1. 


\section{References}

Amante, C. and Eakins, B. W., 2009. ETOPO1 1 Arc-Minute Global Relief Model: Procedures, Data Sources and Analysis. Technical report, NOAA Technical Memorandum NESDIS NGDC-24. 19 pp.

Arabelos, D., 2000. Intercomparisons of the global DTMs ETOPO5, TerrainBase and JGP95E. Physics and Chemistry of the Earth, Part A: Solid Earth and Geodesy 25(1), pp. $89-$ 93.

Bamber, J., 2001. Greenland 5 km DEM, Ice Thickness, and Bedrock Elevation Grids.

Becker, J. J., Sandwell, D. T., Smith, W. H. F., Braud, J., Binder, B., Depner, J., Fabre, D., Factor, J., Ingalls, S., Kim, S.-H., Ladner, R., Marks, K., Nelson, S., Pharaoh, A., Trimmer, R., Von Rosenberg, J., Wallace, G. and Weatherall, P., 2009. Global Bathymetry and Elevation Data at 30 Arc Seconds Resolution: SRTM30_PLUS. Marine Geodesy 32(4), pp. 355371.

Berry, P. A. M., 1999. Global digital elevation models fact or fiction? Astronomy \& Geophysics 40(3), pp. 3.10-3.13.

Berry, P. A. M., Hilton, R., Johnson, C. P. D. and Pinnock, R. A., 2000. ACE: a new GDEM incorporating satellite altimeter derived heights. In: ERS-Envisat Symposium, Vol. SP-461, ESA, Gothenburg, Sweden.

Berry, P. A. M., Smith, R. and Benveniste, J., 2008. ACE2: the new global digital elevation model. In: IAG International Symposium on Gravity, Geoid \& Earth Observation, IAG, Chania, Crete.

Berry, P., Garlick, J. and Smith, R., 2007. Near-global validation of the SRTM DEM using satellite radar altimetry. Remote Sensing of Environment 106(1), pp. 17 - 27.

Berthier, E., Arnaud, Y., Vincent, C. and Rémy, F., 2006. Biases of SRTM in high-mountain areas: Implications for the monitoring of glacier volume changes. Geophysical Research Letters 33(8), pp. L08502.

Carter, J. R., 1992. The Effect Of Data Precision On The Calculation Of Slope And Aspect Using Gridded Dems. Cartographica: The International Journal for Geographic Information and Geovisualization 29, pp. 22-34.

Chow, T. E. and Hodgson, M. E., 2009. Effects of lidar postspacing and DEM resolution to mean slope estimation. International Journal of Geographic Information Science 23, pp. 1277-1295.

Cogley, J. G., 1985. Hypsometry of the continents. Zeitschrift für Geomorphologie Suppl.-Bd. 53, pp. 48.

Danielson, J. J. and Gesch, D. B., 2011. Global multi-resolution terrain elevation data 2010 (GMTED2010). U.S. Geological Survey Open-File Report 2011-1073 ., pp. 1-34.

Farr, T. G., Rosen, P. A., Caro, E., Crippen, R., Duren, R., Hensley, S., Kobrick, M., Paller, M., Rodriguez, E., Roth, L., Seal, D., Shaffer, S., Shimada, J., Umland, J., Werner, M., Oskin, M., Burbank, D. and Alsdorf, D., 2007. The Shuttle Radar Topography Mission. Review of Geophysics 45, pp. RG2004.

Fielding, E. J., Isacks, B., Barazangi, M. and Duncan, C., 1994. How flat is Tibet? Geology 22, pp. 163-167.
Fox, M., Dorrell, B. and Haskell, L., 2008. Got Mountains? Challenges of Modeling SRTM and Other Terrain Data to Suit Aviation Applications. In: Proceedings of Esri 28th Annual International User Conference, San Diego, California.

Gesch, D. B., Verdin, K. L. and Greenlee, S. K., 1999. New land surface digital elevation model covers the Earth. Eos, Transactions American Geophysical Union 80(6), pp. 69-70.

GLOBE Task Team, Hastings, D. A., Dunbar, P. K., Elphingstone, G. M., Bootz, M., Murakami, H., Maruyama, H., Masaharu, H., Holland, P., Payne, J., Bryant, N. A., Logan, T. L., Muller, J. P., Schreier, G. and MacDonald, J. S., 1999. The Global Land One-kilometer Base Elevation (GLOBE) Digital Elevation Model, Version 1.0. Digital data base on the World Wide Web and CD-ROMs.

GRASS Development Team, 2014. Geographic Resources Analysis Support System (GRASS GIS) Software, Version 6.4.5. http://grass.osgeo.org, [accessed 20 January 2015].

Grohmann, C. H., 2015. Effects of spatial resolution on slope and aspect derivation for regional-scale analysis. Computers \& Geosciences 77, pp. 111-117.

Grohmann, C. H., Smith, M. J. and Riccomini, C., 2010. Multiscale Analysis of Topographic Surface Roughness in the Midland Valley, Scotland. Geoscience and Remote Sensing, IEEE Transactions on 49(4), pp. 1200-1213.

Harrison, C. G. A., Miskell, K. J., Brass, G. W., Saltzman, E. S. and Sloan, J. L., 1983. Continental hypsography. Tectonics 2(4), pp. 357-377.

Hastings, D. A. and Dunbar, P. K., 1998. Development \& Assessment of the Global Land One-km Base Elevation Digital Elevation Model (GLOBE). ISPRS Archives 32(4), pp. 218 221.

Hijmans, R. J., Cameron, S. E., Parra, J. L., Jones, P. G. and Jarvis, A., 2005. Very high resolution interpolated climate surfaces for global land areas. International Journal of Climatology 25(15), pp. 1965-1978.

Hunter, J. D., 2007. Matplotlib: A 2D graphics environment. Computing In Science \& Engineering 9(3), pp. 90-95. Available at http://matplotlib.sourceforge.net/, last access 06/06/2011.

Jakobsson, M., Mayer, L., Coakley, B., Dowdeswell, J. A., Forbes, S., Fridman, B., Hodnesdal, H., Noormets, R., Pedersen, R., Rebesco, M., Schenke, H. W., Zarayskaya, Y., Accettella, D., Armstrong, A., Anderson, R. M., Bienhoff, P., Camerlenghi, A., Church, I., Edwards, M., Gardner, J. V., Hall, J. K., Hell, B., Hestvik, O., Kristoffersen, Y., Marcussen, C., Mohammad, R., Mosher, D., Nghiem, S. V., Pedrosa, M. T., Travaglini, P. G. and Weatherall, P., 2012. The International Bathymetric Chart of the Arctic Ocean (IBCAO) Version 3.0. Geophysical Research Letters 39(12), pp. L12609.

Jasiewicz, J. and Stepinski, T. F., 2013. Geomorphons a pattern recognition approach to classification and mapping of landforms. Geomorphology 182, pp. $147-156$.

Jenny, B., Jenny, H. and Hurni, L., 2011. Terrain Generalization with Multi-scale Pyramids Constrained by Curvature. Cartography and Geographic Information Science 38(2), pp. 110 116.

Jet Propulsion Laboratory, 2014. U.S. Releases Enhanced Shuttle Land Elevation Data. Acessed Jan 15, 2015. 
Kobrick, M. and Crippen, R., 2015. Merging Datasets to Produce NASADEM. In: Geoscience and Remote Sensing Symposium (IGARSS), 2015 IEEE International, Milan, Italy.

Kobrick, M., Farr, T. G. and Crippen, R., 2011. A Merged Global Digital Topographic Data Set - Progress Report. NASA, Vancouver, Canada.

Krieger, G., Zink, M., Fiedler, H., Hajnsek, I., Younis, M., Huber, S., Bachmann, M., Gonzalez, J., Schulze, D., Boer, J., Werner, M. and Moreira, A., 2009. The TanDEM-X Mission: Overview and status. In: Radar Conference, 2009 IEEE, pp. 15 .

Llobera, M., 2001. Building Past Landscape Perception With GIS: Understanding Topographic Prominence. Journal of Archaeological Science 28(9), pp. 1005 - 1014.

Maizlish, A., 2003. Prominence and Orometrics: A Study of the Measurement of Mountains. (accessed 29 January 2015).

Maizlish, A., 2011. Peaklist.org. (acessed 29 January 2015).

Mayer, L., 2000. Application of digital elevation models to macroscale tectonic geomorphology. In: M. A. Summerfield (ed.), Geomorphology and Global Tectonis, John Wiley, pp. 15-27.

Miliaresis, G. C., 2006. Geomophometric mapping of Asia Minor from globe digital elevation data. Geografiska Annaler: Series A, Physical Geography 88(3), pp. 209-221.

Moore, I. D., Grayson, R. B. and Ladson, A. R., 1991. Digital terrain modelling: A review of hydrological, geomorphological, and biological applications. Hydrological Processes 5, pp. 3-30.

Neteler, M., Bowman, M. H., Landa, M. and Metz, M., 2012. GRASS GIS: A multi-purpose open source GIS. Environmental Modelling \& Software 31, pp. 124-130.

New, M., Lister, D., Hulme, M. and Makin, I., 2002. A highresolution data set of surface climate over global land areas. Climate Research 21(1), pp. 1-25.

NGA - National Geospatial-Intelligence Agency, 2014. NGA releases high-resolution elevation data to public. Acessed Jan 15,2015

Oliphant, T., 2006. Guide to NumPy. Trelgol Publishing.

Podobnikar, T., 2012. Detecting Mountain Peaks and Delineating Their Shapes Using Digital Elevation Models, Remote Sensing and Geographic Information Systems Using Autometric Methodological Procedures. Remote Sensing 4(3), pp. 784809.

Python Software Foundation, 2013. Python Programming Language, version 2.7. Available at http://www . python.org/, last access 15/Aug/2013.

Sandwell, D. T. and Smith, W. H. F., 1997. Marine gravity anomaly from Geosat and ERS 1 satellite altimetry. Journal of Geophysical Research 102, pp. 10039-10054.

Schmidt, G. A., Ruedy, R., Hansen, J. E., Aleinov, I., Bell, N., Bauer, M., Bauer, S., Cairns, B., Canuto, V., Cheng, Y., Del Genio, A., Faluvegi, G., Friend, A. D., Hall, T. M., Hu, Y., Kelley, M., Kiang, N. Y., Koch, D., Lacis, A. A., Lerner, J., Lo, K. K., Miller, R. L., Nazarenko, L., Oinas, V., Perlwitz, J., Perlwitz, J., Rind, D., Romanou, A., Russell, G. L., Sato, M.,
Shindell, D. T., Stone, P. H., Sun, S., Tausnev, N., Thresher, D. and Yao, M.-S., 2006. Present-Day Atmospheric Simulations Using GISS ModelE: Comparison to In Situ, Satellite, and Reanalysis Data. Journal of Climate 19(2), pp. 153-192.

Smith, R. G. and Berry, P. A. M., 2011. Evaluation of the differences between the SRTM and satellite radar altimetry height measurements and the approach taken for the ACE2 GDEM in areas of large disagreement. Journal of Environmental Monitoring 13 , pp. 1646-1652.

Smith, W. H. F. and Sandwell, D. T., 1997. Global seafloor topography from satellite altimetry and ship depth soundings. Science 277, pp. 1957-1962.

Tachikawa, T., Hato, M., Kaku, M. and Iwasaki, A., 2011. Characteristics of ASTER GDEM version 2. In: Geoscience and Remote Sensing Symposium (IGARSS), 2011 IEEE International, pp. 3657-3660.

Takaku, J., Tadono, T. and Tsutsui, K., 2014. Generation of High Resolution Global DSM from ALOS PRISM. ISPRS - International Archives of the Photogrammetry, Remote Sensing and Spatial Information Sciences XL-4, pp. 243-248.

The SciPy community, 2013. SciPy Reference Guide - Release 0.13.0.

Thomas, C. D., Cameron, A., Green, R. E., Bakkenes, M., Beaumont, L. J., Collingham, Y. C., Erasmus, B. F. N., de Siqueira, M. F., Grainger, A., Hannah, L., Hughes, L., Huntley, B., van Jaarsveld, A. S., Midgley, G. F., Miles, L., Ortega-Huerta, M. A., Townsend Peterson, A., Phillips, O. L. and Williams, S. E., 2004. Extinction risk from climate change. Nature 427(6970), pp. 145-148.

Thompson, S. L. and Pollard, D., 1995. A Global Climate Model (GENESIS) with a Land-Surface Transfer Scheme (LSX). Part I: Present Climate Simulation. Journal of Climate 8(4), pp. 732-761.

Wood, J., 1996. Scale-based characterization of Digital Elevation Models. In: D. Parker (ed.), Innovations in GIS 3, London: Taylor and Francis, chapter 13.

Zambelli, P., Gebbert, S. and Ciolli, M., 2013. Pygrass: An Object Oriented Python Application Programming Interface (API) for Geographic Resources Analysis Support System (GRASS) Geographic Information System (GIS). ISPRS International Journal of Geo-Information 2(1), pp. 201-219.

Zhang, W. and Montgomery, D., 1994. Digital elevation model grid size, landscape representation, and hydrologic simulations. Water Resources Research 30(4), pp. 1019-1028.

\section{ACKNOWLEDGEMENTS}

This study was supported by CNPq (306294/2012-5, 307647/2015$3)$ and FAPESP (2009/17675-5 , 2016/03188-9) research grants to CHG and is co-funded by two collaborative Dimensions of Biodiversity-BIOTA grants supported by FAPESP $(2012 / 50260-$ 6, 2013/50297-0), NSF (DEB 1241066, DEB 1343578)), and NASA. I want to thank Dean Gesch for the fruitful discussions on the subject and the anonymous reviewers for their criticism and suggestions, which helped to improve this paper. 